\title{
Giraffe
}

When the young jailer found that, at the prisoners' monthly physical examination, every time there was an increase in height, it was exclusively in the neck, he reported to the warden, "Sir, the windows are too high." The answer was, "No, it's the years the prisoners are longing for."

The kindly jailer did not know the look of years, did not know the birthplace of years nor the whereabouts of years, and thus, he went night after night to the zoo to wait for them under the giraffe pen.

\section{The Black Crystal of No Substance}

"We should turn off the light before undressing, otherwise LIGHT will stay on our flesh."

"Because of its hold on you?"

"Because of its being an insulator."

"What about the moon then?"

"Even the stars are the same." After the light is turned off, the curtain falls down; outside the window is nothing but the stiff night. Inside the house a person, after having lost his hair, has lost also his lips and tongue; the arms each from its back and shoulder, from the breasts and waist, disappear; his legs and his ankles go a little bit later. After that, what is left is the so-called BEING.

N'ETRE PAS. They were not being dissolved by darkness; they took part in and purified DARKNESS and thus: Alas, how difficult it is to make a black crystal of no substance.

Translated by Wang Ching-lin and William Golightly 